\title{
ANALISIS PERBANDINGAN METODE ZMIJEWSKI DAN GROVER DALAM MEMPREDIKSI KEBANGKRUTAN BANK YANG TERDAFTAR PADA BEI TAHUN 2015-2019
}

\author{
Amel Dewi Utari \\ Universitas Negeri Surabaya \\ amel.17080574116@mhs.unesa.ac.id
}

\begin{abstract}
Bankruptcy is the lowest position in a company because of financial problems. This problem is due to the failure of the company's management efforts to follow up on financial problems. Using Zmijewski and Grover methods, this study chose this method because both methods have three series calculation instruments and the same ROA. Therefore, an early warning signal is needed to anticipate the bankruptcy that occurs. The population in this study includes as many as 42 companies from the banking sector listed on the Indonesia Stock Exchange in 2015-2019. By using the purposive sampling technique, a total sample of 12 banking. The data used is secondary data from the company's annual financial statements. This research was processed with SPSS to obtain the results of significant differences between the Zmijewski model and the Grover model in predicting bankruptcy in banking listed on the Indonesia Stock Exchange from 2015 to 2019.
\end{abstract}

Keywords: bankruptcy prediction; grover method; zmijewski method

\section{PENDAHULUAN}

Perbankan merupakan hal yang tidak bisa terlepas dari perkembangan perekonomian suatu negara. Terlebih lagi pada bank konvensional, karena memiliki tingkat integrasi yang tinggi pada perekonomian suatu negara. Oleh karena itu perbankan sering disebut sebagai gambaran roda perekenomian suatu negara (Baroroh, 2012). Terlihat pada peranan dan fungsi intermediasi, lembaga perbankan berperan sebagai roda perputaran keuangan di Indonesia, terlihat pada nasabah yang memiliki kelebihan uang melakukan penyimpanan di bank (surplus unit), kemudian menyalurkan kepada pihak nasabah yang lebih memerlukan yang melakukan pengkreditan (deficit unit) (Habriyanto, 2011). Peran intermediasi pada lembaga perbankan dapat mengatur dan menjadi roda penggerak perputaran yang menunjang perekonomian di Indonesia.Dengan demikian perlunya perhatian khusus mengenai kondisi keuangan perbankan untuk mengatisipasi keberlangsungan dimasa mendatang dengan melakukan prediksi kebangkrutan.

Dewasa ini telah banyak lembaga keuangan perbankan (jasa perbankan) di Indonesia yang berkembang, dan hal ini tentunya akan menimbulkan perlombaan antar lembaga keuangan untuk menarik hati para calon nasabahnya. Tidak hanya bank-bank konvensional saja yang menjadi saingannya, tetapi juga lembaga penyedia jasa keuangan yang lainnya. Oleh karena itu agar tetap dapat bersaing, bertahan dan tetap berkembang di masa mendatang, perbankan harus konsisten dalam memuaskan nasabah agar tidak beralih ke bank yang lain dengan cara selalu memperhatikan segi pelayanan jasanya. Tidak hanya segi pelayanan jasa, untuk tetap bertahan dan dapat beradaptasi dengan setiap perubahan iklim ekonomi, maka perbankan perlu melakukan sistem antisipasi guna memprediksi keberlangsungan di masa mendatang dengan sistem peringatan dini (early warning). Sistem ini akan memberikan deteksi adanya problem keuangan yang mengancam keberlangsungan operasional bank agar bank tidak mengalami kebangkrutan. Indikator yang paling akurat untuk perhitungan analisis peringatan dini adalah laporan keuangan perusahaan (Kurniawati \& Kholis, 2016).

Fenomena kebangkrutan bank di Indonesia dapat dilihat berdasarkan data dari Lembaga Pinjaman Simpanan (LPS) tercatat sebanyak 74 bank telah dilikuiditas sejak tahun 2008 hingga tahun 2017. Mayoritas bank yang dilikuidasi adalah bank BPR, yakni sebanyak 74 dan satu bank umum (www.lps.go.id, 2020). Oleh karena itu peringatan dini perlu guna bahan introspeksi perusahaan 
Amel Dewi Utari. Analisis Perbandingan Metode Zmijewski dan Metode Grover dalam Memprediksi Kebangkrutan Bank yang Terdaftar pada BEI 2015-2019.

dalam melihat kondisi perusahaan dimasa mendatang. Hasil analisi prediksi selain digunakan untuk pihak internal perusahaan, juga sangat berguna bagi pihak eksternal. Salah satunya ialah bagi investor untuk mengambil keputusan mengenai investasi jangka panjangnya.

Menurut Dendawijaya (2009:118), untuk mengukur kemampuan manajemen bank dalam menghasilkan keuntungan secara keseluruhan mengunakan ROA. ROA adalah rasio profitabilitas yang berfungsi mengukur kemampuan sebuah bank dalam menghasilkan laba pada tahun berjalan yang dapat digunakan dimasa yang akan datang. Penilaian rasio ini menunjukkan seberapa baik perusahan tersebut, apabila tingkat ROA tinggi maka keuntungan yang didapatkan juga tinggi, dan posisi bank juga terlihat baik dalam penggunaan asetnya. Hal ini juga konsiten dengan Kasmad (2018), untuk menentukan tingkat kesehatan perbankan di Indonesia, bank lebih mementingkan nilai ROA daripada ROE. Hal ini dikarenakan Bank Indonesia memprioritaskan nilai profitabilitas yang diukur dari asset yang dananya sebagian besar berasal dari simpanan masyarakat, untuk itu nilai ROA lebih mempresentasikan dalam pengukuran nilai profitabilitas perbankan.

Tabel 1.

TINGKAT ROA PERBANKAN YANG MENGALAMI PENURUNAN TAHUN 2017- 2019

\begin{tabular}{lllccc}
\hline \multirow{2}{*}{ No } & \multirow{2}{*}{ KODE } & \multicolumn{2}{c}{ PERUSAHAAN } & \multicolumn{3}{c}{ TINGKAT ROA } \\
& & \multicolumn{2}{c}{$\mathbf{2 0 1 7}$} & $\mathbf{2 0 1 8}$ & $\mathbf{2 0 1 9}$ \\
\hline 1 & ARTO & Bank Artos Indonesia Tbk. & $-1,48$ & $-2,76$ & $-15,89$ \\
2 & BBMD & Bank Mestika Dharma Tbk. & 3,19 & 2,96 & 2,72 \\
3 & BBRI & Bank Rakyat Indonesia (Persero) Tbk. & 3,69 & 3,68 & 3,50 \\
4 & BBTN & Bank Tabungan Negara (Persero) Tbk. & 1,71 & 1,34 & 0,13 \\
5 & BINA & Bank Ina Perdana Tbk. & 0,82 & 0,50 & 0,23 \\
6 & BJBR & BPD Jawa Barat dan Banten Tbk. & 2,01 & 1,71 & 1,68 \\
7 & BJTM & BPD Jawa Timur Tbk. & 3,12 & 2,96 & 2,73 \\
8 & BMAS & Bank Maspion Indonesia Tbk. & 1,60 & 1,54 & 1,13 \\
9 & BSIM & Bank Sinarmas Tbk. & 1,26 & 0,25 & 0,23 \\
10 & BVIC & Bank Victoria International Tbk. & 0,64 & 0,33 & 0,09 \\
11 & BEKS & PT Bank Pembangunan Daerah Banten Tbk. & $-1,00$ & $-1,42$ & $-1,70$ \\
12 & DNAR & PT Bank Oke Indonesia Tbk. & 0,6 & 0,4 & $-0,3$ \\
\hline
\end{tabular}

Sumber : data diolah (2020)

Tabel 1, data tingkat penurunan ROA (return of asset) beberapa bank konvensional yang terdaftar pada Bursa Efek Indonesia tahun 2017-2019. Padahal, diketahui bahwa pentingnya tingkat ROA dalam mengukur kemampuan manajemen bank untuk menghasilkan laba yang besar. Semakin tingkat ROA, maka semakin besar tingkat keuntungan yang diraih, dan semakin baik pula posisi perbankan dalam pemanfaatan asetnya. Oleh karena, perbankan harus dapat terus mempertahankan dan meningkatkan tingkat ROA agar mendapatkan keuntungan yang besar.

Metode dalam memprediksi kebangkrutan sebuah perusahaan telah berkembang dewasa ini. Berbagai metode tersebut mempunyai masing-masing hasil yang bebeda beda dalam memprediksi sebuah perusahaan, sehingga diperlukan metode yang tepat dan akurat. Metode prediksi yang digunakan pada penelitian ini diantaranya adalah metode Zmijewski dan metode Grover. Metode Zmijewski (1984) adalah model perhitungan prediksi kebangkrutan yang menggunakan rasio leverage, dan likuiditas suatu perusahaan. Dalam metode ini, ada beberapa indikator rasio keuangan yang diperhatikan seperti; return on assets, debt ratio, dan current ratio. Metode analisis Grover (2001) adalah metode yang dibuat dengan indikator perancangan dan pengevaluasian kembali metode prediksi Altman ZScore (Putra \& Septiani, 2017). Model grover memerhatikan beberapa indikator rasio keuangan seperti; return on asset (ROA), working capital to total assets, dan earnings before interest and taxes/total assets, return on asset (ROA), rasio-rasio keuangan ini digunakan untuk menunjukkan kemampuan perusahaan dalam menghasilkan laba kotor dari aktiva perusahaannya.

Metode penelitian untuk mengukur kebangkrutan perbankan yang sering digunakan adalah metode Altman, metode Grover, metode Springate, metode Ohslon, dan metode Zmijewski. Penelitian ini 
memilih dua metode yang menggunakan perhitungan rasio ROA, yaitu; metode Zmijewsi dan metode Grover. Penggunaan dua metode tersebut dikarenakan kedua metode ini sama-sama menggunakan rasio perhitungan ROA, dan kedua metode ini juga memiliki tiga instrumen perhitungan yang seri. Metode Zmijewski dengan instrumen perhitungan ROA, debt ratio, dan current ratio. Metode Grover memiliki instrumen perhitungan working capital to total assets, earning before interest and taxes to total asset, dan ROA (Prihanthini \& Sari, 2013). Berdasarkan latar belakang di atas, penelitian ini bertujuan untuk menganalisis perbandingan metode Zmijewski dan Grover dalam memprediksi kebangkrutan bank yang terdaftar pada BEI tahun 2015-2019.

\section{KAJIAN PUSTAKA DAN PENGEMBANGAN HIPOTESIS}

\section{Signaling Theory}

Signaling theory merupakan sebuah tindakan manajemen perusahaan untuk melihat prospek perusahaan pada masa lalu hingga masa depannya (Pangkey et al., 2018). Menurut Tuvadaratragool, (2013) untuk mengetahui adanya sinyal kegagalan atau kebangkrutan pada perusahaan diperlukan penggunaan informasi laporan keuangan. Untuk hasil dari teori ini dapat memberi sinya positif (good news), maupun negatif (bad news). Hasil informasi ini akan memberi petunjuk kepada investor mengenai prospek perusahaan guna menentukan hasil keputusan investor. Secara garis besar peringatan teori sinyal sangat berperan penting terhadap kemajuan dan prospek perusahaan kedepannya, terlebih lagi pada sektor perbankan yang menjadi pelopor dalam perekonomian suatu negara.

\section{Kebangkrutan}

Kebangkrutan merupakan posisi terpuruknya sebuah perusahaan yang sangat dihindari, karena kelalaian manajemen perusahan dalam menindaklanjuti permasalahan keuangan yang terjadi. Sedangkan financial distress adalah posisi awal mula dari kesulitan keuangan perusahaan yang mungkin akan menjadi bangkrut apabila manajemen perusahan lalai mengatasinya. Kesulitan keuangan dimulai ketika perusahaan tidak dapat memenuhi tenggat waktu kewajibannya (Mulyati \& Ilyasa, 2020).

\section{Prediksi Kebangkrutan}

Kebangkrutan sebuah perusahan sebenarnya dapat diprediksi jauh sebelum perusahan mengalami gulung tikar. Prediksi ini akan membantu manajemen perusahaan dalam mengambil keputusan dan menentukan sikap terhadap yang mengalami kesulitan keuangan (Pangkey et al., 2018). Menurut Gitman (2011) terdapat tiga faktor yang mengakibatkan kebangkrutan pada sebuah perusahaan, yaitu : kesalahan manajemen; kondisi ekonomi; c. siklus hidup perusahaan.

\section{Penanggulangan Potensi Kebangkrutan}

Menurut Pustylnick (2012), terdapat dua solusi jika suatu perusahaan mengalami kesulitan keuangan seperti: Restrukturasi hutang yaitu, perpanjangan yang disepakti oleh kreditur dan debitur untuk menambah jangka waktu dalam melunasi hutanya agar perusahaan memiliki kas yang cukup; Perubahan dalam manajemen, hal ini merupakan langkah yang rawan untuk dilakukan karena pengambilan keputusan ini sangat menentukan nasib perusahaan kedepanya. Perubahan manajemen ini bisa dilakukan dengan langkah penggantian jajaran manajemen yang lebih berkompeten.

\section{Pihak-pihak yang Memerlukan Informasi Prediksi Kebangkrutan}

Pihak-pihak yang membutuhkan informasi prediksi kebangkrutan ialah: Manajemen Perusahaan, diharapkan menjadi intopeksi perusahaan dalam menghindari kebangkrutan; Investor, membantu keputusan investor dalam melakukan investasi; Kreditur, digunaan untuk memberikan kebijakan dan keputusan mengenai keputusan kreditor keapda calon kreditur; Otoritas Pembuat Peraturan (regulatory authorities), memberikan informasi kepada pemerintah untuk mengeluarkan peraturan yang dapat melindungi kepentingan masyarakat dari kerugian yang menggangu stabiliais ekonomi; Auditor, berfungsi untuk melakukan audit, dan memberikan penilaian pada suatu perusahaan (Putri, 2019). 
Amel Dewi Utari. Analisis Perbandingan Metode Zmijewski dan Metode Grover dalam Memprediksi Kebangkrutan Bank yang Terdaftar pada BEI 2015-2019.

\section{Metode Zmijewski}

Zmijewski (1984) adalah metode prediksi kebangkrutan yang menggunakan teknik probit dalam indakator perhitungannya. Pada tahun 1984 penggunan metode Zmijewski memprediksi sebanyak 40 perusahaan bangkrut dan 800 perusahaan tidak bangkrut (Avenhuis, 2013). Metode ini memiliki instrumen perhitungan yang memfokuskan pada kemampuan aset untuk menutupi kewajibanya seperti, return on asset (X1), debt ratio (X2), dan current ratio (X3). Metode ini memiliki rumus (1).

$$
X-\text { Score }=-4,3-4,5 X 1+5,7 X 2-0,004 X 3
$$

Zmijeski memiliki nilai cut-off, apabila hasil perhitungan melebihi skor 0 diprediksi perusahaan berpotensi bangkrut, dan apabila hasil perhitungan memiliki nilai kurang dari 0 diprediksi perusahaan tidak akan bangkrut atau dalam kondisi sehat (Prihanthini \& Sari, 2013).

\section{Metode Grover}

Metode Grover diciptakan oleh Jeffrey S. Metode ini merupakan perkembangan, dan penilian ulang terhadap model Altman (Prihanthini \& Sari, 2013). Metode ini memiliki instrumen perhitungan working capital to total assets (X1), earning before interest and taxes to total asset (X2), dan return on asset (X3). Metode ini memiliki rumus (2):

$$
G-\text { Score }=1,650 \times 1+3,404 \times 2-0,016 \times 3+0,057
$$

Metode Grover memiliki nilai kategori, apabila skor kurang atau sama dengan -0,02 diprediksi perusahaan dalam kondisi bangkrut. Sedangkan apabila skor lebih atau sama dengan 0 diprediksi perusahan dalam keadaan tidak bangkrut atau sehat (Halimatusyakdiah et al.,2015).

\section{Prediksi Kebangkrutan Perbankan dengan Metode Zmijewski}

Metode Zmijewski merupakan metode yang dalam perhitunganya mengutamakan beberapa rasio dalam mengukur kinerja perusahaan seperti leverage, dan likuiditas. Dengan instrumen perhitungan return on asset, debt ratio, dan current ratio. Metode ini adalah metode yang dapat digunakan dalam memprediksi kebangkrutan perusahaan dimasa mendatang (Husein \& Pambekti, 2015). Hasil ini menujukkan bahwa instrumen perhitungan metode Zmijewski mampu menggambarkan kondisi perusahan kedepanya. Metode Zmijewski juga menjadi metode terakurat dalam memprediksi kebangkrutan perusahaan manufaktur diantara dua metode lainnya seperti Altman dan Springate (Gunawan et al., 2017).

H1: Metode Zmijewski dapat memprediksi kebangkrutan perbankan yang terdaftar pada Bursa Efek Indonesia tahun 2015-2019.

\section{Prediksi Kebangkrutan Perbankan dengan Metode Grover}

Metode Grover merupakan metode pengembangan ulang terhadap metode Altman, dengan instrumen perhitungan working capital to total assets, earning before interest and taxes to total asset, dan return on asset Syamni et al.(2018). Pada penelitian Prihanthini \& Maria M Ratna Sari, (2013), menyatakan perhitungan analisis Grover merupakan analisis paling akurat untuk memprediksi kebangkrutan perusahaan Food and Beverage di Indonesia daripada tiga metode lain, seperti metode Zmijewski, Altman, dan Springate. Hal ini konsisten dengan penelitian (Pakdaman, 2018; Qamruzzaman \& Jianguo, 2016), menyatakan bahwa instrumen perhitungan Grover mempunyai kemampuan prediksi yang baik dalam memprediksi kebangkrutan perusahaan di Tehran Stock Exchange, dan Lembaga Keuangan di Bangladesh, dibandingkan tiga model lainnya, model Zmijewski, Altman, dan Springate.

H2: Metode Grover dapat memprediksi kebangkrutan perbankan yang terdaftar pada Bursa Efek Indonesia tahun 2015-2019.

\section{Perbandingan Metode Zmijewski dan Grover dalam Memprediksi Kebangkrutan Perbankan}

Pada penelitian ini metode yang digunakan ialah metode Zmijewski dan Grover dalam memprediksi kebangkrutan perbankan di Indonesia. Pengambilan kedua metode ini dikarenakan memiliki 2 
kesamaan; Pertama, memiliki tiga instrumen perhitungan yang seri sebanyak tiga; Kedua; menggunakan instrumen perhitungan yang sama yaitu return on asset (ROA). Penelitian ini mengutamakan rasio ROA karena menurut Kasmad (2018), Bank Indonesia lebih mementingkan penilaian rasio ROA dalam memperoleh keuntungan secara keseluruhan. Hasil dari penelitian ini akan menjelaskan metode mana yang paling tepat dalam memprediksi kondisi perbankan pada BEI tahun 2015-2019.

H3: Terdapat perbedaan analisis prediksi kebangkrutan bank metode Grover yang terdaftar pada BEI tahun 2015-2019.

\section{METODE PENELITIAN}

Pendekatan secara kuantitatif dipilih dalam penelitian ini, yang melakukan analisis terkait hubungan masing-masing variabel terhadap dua metode yang digunakan dalam memprediksi kebangkrutan perbankan. Periode pengamatan ditentukan pada kurun waktu 5 tahun dimulai yaitu tahun 2015 hingga tahun 2019. Data sekunder penelitian ini didapatkan dari annual report perbankan. Sampel penelitian ialah sektor perbankan yang tercatat di Bursa Efek Indonesia tahun 2015-2019 sebanyak 12 sampel pada 5 tahun pengamatan yang telah diseleksi dengan teknik purposive sampling. Penelitian ini menggunakan teknik analisis regesi logistik dengan alat statistik sofware IBM Statistics 26. Langkah-langkah yang pertama adalah tabulasi data, kemudian dilakukan analisis uji beda yaitu: uji normalitas, uji parsial (uji t), dan uji beda T-test.

\section{HASIL DAN PEMBAHASAN}

\section{Analisis Prediksi Kebangkrutan Zmijewski}

Langkah awal yang dilakukan ialah tabulasi metode Zmijewski, dengan instrumen perhitungan: return on asset (ROA), debt ratio (DR), dan current ratio (CR). Pada score prediksi metode ini memiliki rata-rata perbankan dalam kategori bangkrut. Hal ini terlihat hanya terdapat satu perbankan yaitu, bank Mestika Dharma Tbk yang konsisten dalam 5 tahun terakhir dalam kategori sehat, dan perbankan lainnya dengan mengalami kebangkrutan pada kurun waktu 2015-2019.

\section{Analisis Prediksi Kebangkrutan Grover}

Langkah awal juga dilakukan dengan tabulasi score metode Grover, dengan masing-masing instrumen perhitungan: WCTA, EBITTA, dan ROA. Penilaian Grover dilihat dari score rata-rata memiliki nilai positif yang artinya bahwa, perbankan dalam kategori sehat. Hal ini terlihat hanya terdapat satu perbankan, dalam satu tahun yang diprediksi mengalami bangkrut yaitu Bank Artos Indonesia Tbk. Sampel perbankan lainnya diprediksi tidak mengalami kebangkrutan atau dalam kategori sehat pada kurun waktu 2015-2019. Hasil metode Grover sesuai dengan kenyataan yang terjadi di lapangan, bahwa duabelas sampel tidak mengalami kebangkrutan pada tahun 2015-2019.

\section{Statistik Deskriptif}

Statistik Deskriptif merupakan analisis statistik yang memberi informasi dengan menampilkan data mulai dari banyaknya sampel, standart deviasi, angka minimum, angka maksimum, dan rata-rata data penelitian. Statistik Deskrptif mendiskrpsikan data sampel menjadi data yang sederhana dan mudah dipahami oleh pembaca (Ghozali, 2016:19). Hasil statistik deskriptif, diketahui nilai minumum metode Zmijewski sebesar -1,1313, sedangkan nilai minimum metode Grover sebesar 0,127. Kemudian nilai max metode Zmijewski sebesar 1,349, sedangkan Grover sebesar 0,897. Pada nilai sum untuk metode Zmijewski sebesar 12,597, dan Grover sebesar 28,322. Untuk nilai mean yang dihasilkan metode Zmijewski diketahui sebesar 0,20995, sedangkan pada Grover memiliki nilaisebesar 0,47203. Kemudian untuk nilai standart deviasi untuk metode Zmijewski diketahui sebesar 0,473438, sedangkan metode Grover memiliki nilai sebesar 0,143553. Dari data di atas, diketahui bahwa metode Zmijewski nilainya lebih besar dari metode Grover. 
Amel Dewi Utari. Analisis Perbandingan Metode Zmijewski dan Metode Grover dalam Memprediksi Kebangkrutan Bank yang Terdaftar pada BEI 2015-2019.

\section{Uji Persyaratan Analisis}

Pengujian persyaratan analisis normalitas dapat diketahui apakah data berdistribusi normal atau tidak normal (Ghozali, 2016:154). Pengambilan keputusan dilakukan untuk menentukan uji hipotesis yang di gunakan peneliti, apabila data berdistribusi normal maka menggunakan Paired Sample T-test (statistik parametik), dan apabila hasil menunjukkan bahwa data tidak berdistribusi normal maka uji hupotesis menggunakan Wilcoxon Signed Rank T-test (statistik non-parametik). Hasil uji normalitas dilakukan dengan membandingkan hasil Asymp. Sig (2-tailed) dengan signifikansi ( $\square$ ) sebesar 0,05 atau 5\%. Apabila nilai Asymp. Sig (2-tailed) lebih besar dari 0,05 maka data berdistribusi normal, dan sebaliknya. Setelah dilakukan uji normalitas, diketahui bahwa metode Zmijewski dan Grover dikategorikan pada data berdistribusi tidak normal karena nilai Asymp. Sig $\geq 0,05$. Terlihat dengan nilai Asymp. Sig metode Zmijewski sebesar 0,021 dan metode Grover sebesar 0,075. Dengan demikian penelitian ini menggunakan alat statistika nonparametik yaitu Uji Wilcoxon Signed Ranks Test.

\section{Uji Parsial (Uji t)}

Uji Parsial bertujuan mengetahui bagaimana pengaruh variabel bebas terhadap variabel terkait yang dilihat dari hasil thitung masing-masing variabel (Ghozali 2016:171). Pengambilan keputusan uji t dilihat pada besarnya nilai signifikansi, apabila nilainya lebih kecil atau sama dengan 0,05 maka dinyatakan variabel tersebut berpengaruh, dan sebaliknya. Hasil uji t pada metode Zmijewski, memiliki hasil variabel ROA memiliki nilai sig. ,000 dan nilai $t_{\text {hitung }}-35,390$. Diketahui bahwa ROA berpengaruh negatif dan signifikan terhadap metode Zmijewski. Variabel DR, memiliki nilai sig. ,000 dan nilai $t_{\text {hitung }} 88,138$. Diketahui untuk variabel DR berpengaruh positif dan signifikan terhadap metode Zmijewski. Kemudian untuk variabel CR hasil nilai sig. sebesar 0,313 dan nilai $t_{\text {hitung }}$ 0,017. Diketahui bahwa variabel CR berpengaruh positif dan tidak signifikan terhadap metode Zmijewski.

Pada uji t metode Grover memiliki hasil bahwa variabel WCTA hasil nilai sig. ,000 dan nilai $\mathrm{t}_{\text {hitung- }}$ 117,571. Diketahui bahwa WCTA berpengaruh positif dan signifikan terhadap metode Grover. Variabel EBITTA hasil nilai sig. ,000 dan nilai $t_{\text {hitung }}$ 42,184. Diketahui bahwa EBITTA berpengaruh positif dan signifikan terhadap metode Grover. Kemudian untuk variabel ROA memiliki nilai sig. sebesar 0,411 dan nilai t hitung -0,828. Diketahui ROA berpengaruh negatif dan tidak signifikan terhadap metode Grover. Dengan demikan, masing-masing indikator perhitungan pada kedua metode, metode Zmijewski dan Grover sama-sama berpengaruh terhadap prediksi kebangkrutan.

\section{Uji Hipotesis}

Pada uji persyaratan analisi menunjukkan bahwa hasil data tidak berdistribusi normal, oleh karena itu untuk uji hipotesis dilakukan dengan statistik non-parametrik yaitu Wilcoxon Signed Rank T-test. Pada uji hipotesis dasar penilaian dilihat pada nilai Sig. (2-tailed). Apabila lebih kecil dari tingkat signifikansi $(\alpha)$ sebesar 0,05 jadi tidak ada perbedaan analisis prediksi kebangkrutan pada kedua metode, dan apabila lebih besar dari 0,05 terdapat perbedaan analisis prediksi kebangkrutan pada kedua metode.

Tabel 2.

\section{UJI WILCOXON SIGNED RANK TEST METODE ZMIJEWSKI DAN METODE GROVER}

\begin{tabular}{lcc}
\hline \multicolumn{3}{c}{ Test Statistics $^{\text {a }}$} \\
\hline \multicolumn{3}{c}{ METODE GROVER } \\
METODE ZMIJEWKSI \\
M & $-2,904^{\mathrm{b}}$ \\
Asymp. Sig. (2-tailed) &, 004 \\
\hline \multicolumn{2}{c}{ Sumber : Output SPSS (data diolah) }
\end{tabular}

Tabel 2, hasil test statistics, nilai Asymp. Sig. (2-tailed) sebesar 0,004. Hal ini menunjukkan bahwa $0,004<0,05$, dengan demikian terdapat perbedaaan analisis prediksi kebangkrutan pada metode Zmijewski dan metode Grover dalam memperediksi kebangkrutan perbankan. Dengan demikian 
untuk melihat metode mana yang paling tepat dalam memprediksi perbankan yang terdaftar di Bursa Efek Indonesia tahun 2015-2019 dilakukan rekap prediksi pada tabel 3.

Tabel 3.

REKAP PREDIKSI KEBANGKRUTAN METODE ZMIJEWSKI DAN GROVER

\begin{tabular}{ccc}
\hline Prediksi & Zmijewski & Grover \\
\hline Bangkrut & 7 & 0 \\
Tidak Bangkrut & 5 & 12 \\
Total & 5 & 12 \\
$\%$ Akurasi & $41,67 \%$. & $100 \%$. \\
Tipe error & $58,33 \%$ & $0 \%$ \\
\hline
\end{tabular}

Sumber : data diolah (2020)

Pada tabel 3, metode Zmijewski memprediksi 7 perbankan mengalami bangkrut, dan 5 sampel perbankan lainnya dalam kategori sehat. Namun hal ini berbanding terbalik dengan kondisi dilapangan, bahwa pada kenyataannya tidak ada perbankan yang mengalami bangkrut dalam kurun waktu 2015-2019 sehingga metode Zmijewski hanya memiliki tingkat akurasi sebesar 41,67\%, dan tipe eror 58,33\%. Untuk metode Grover pada hasil prediksinya diketahui tidak ada perusahaan yang mengalami kebangkut. Hal ini sesuai dengan kenyataan yang terjadi di lapangan, bahwa sampel perusahaan tidak ada yang mengalami kebangkrutan, sehingga metode Grover memiliki tingkat akurasi $100 \%$ dengan tipe eror $0 \%$.

\section{Analisis Prediksi Kebangkrutan Metode Zmijewski}

Hasil prediksi kebangkrutan metode Zmijewski memiliki prediksi dengan rata-rata bahwa perbankan dalam kategori bangkrut pada tahun 2015-2019. Dari data yang telah disajikan sebanyak tujuh perbankan mengalami kebangkrutan, dan lima lainnya dalam kondisi yang sehat. Untuk masingmasing varibel pada metode Zmijewski diketahui bahwa ROA, DR, dan CR melalui uji parsial (uji t) disimpulkan bahwa dapat mempengaruhi prediksi kebangkrutan. Temuan ini didukung oleh penelitian Munawarah \& Hayati (2019) bahwa secara parsial hanya metode Zmijewski yang dapat memengaruhi prediksi kebangkrutan perusahaan. Temuan ini sejalan dengan penelitian AlAli et al. (2018), Gunawan et al. (2017), dan Munawarah \& Hayati (2019) bahwa metode Zmijewski merupakan metode prediksi kebangkrutan yang paling tepat daripada ketiga metode yang lain seperti metode Grover, Altman, dan Springate.

\section{Analisis Prediksi Kebangkrutan Metode Grover}

Hasil prediksi kebangkrutan metode Zmijewski memiliki prediksi dengan rata-rata bahwa perbankan dalam kategori sehat atau tidak mengalami kebangkrutan pada tahun 2015-2019. Dari data yang telah disajikan sebanyak dua belas sampel perbankan dalam kategori sehat, dan hanya ada satu perbankan dalam satu tahun mengalami kebangkrutan pada tahun 2016. Metode ini merupakan metode yang sesuai dengan kenyataan lapangan yang terjadi, bahwa tidak ada perbankan yang mengalami kebangkrutan pada 2015-2016. Temuan ini sejalan dengan penelitian Aminian et al. (2016); Fauzan \& Sutiono (2017); Pakdaman (2018); dan Prihanthini \& Sari (2013), analisis grover adalah analisis paling akurat dalam memprediksi kepailitan sebuah perusahaan daripada ketiga metode yang lain seperti metode Zmijewski, Altman, Springate, dan Ohlson.

\section{Uji Beda Prediksi Kebangkrutan Antara Metode Zmijewski dan Grover}

Hasil penelitian menunjukkan terdapat perbedaan analisis prediksi kebangkrutan antara metode Zmijewski dan Grover. Temuan ini sejalan dengan penelitian Halimatusyakdiah et al.(2015); Putra \& Septiani (2017) bahwa hasil analisis metode Zmijewski dan Grover terdapat perbedaan hasil analisis, hal ini dikarenakan kedua metode memiliki varian instrumen yang berbeda.

Hasil penelitian ini juga menunjukkan bahwa Grover merupakan analisis yang tepat digunakan untuk memprediksi kebangkrutan perbankan, daripada metode Zmijewski. Hal ini dapat terlihat bahwa sebanyak 12 sampel perbankan dalam kategori sehat dengan tingkat akurasi sebesar $100 \%$. Temuan 
Amel Dewi Utari. Analisis Perbandingan Metode Zmijewski dan Metode Grover dalam Memprediksi Kebangkrutan Bank yang Terdaftar pada BEI 2015-2019.

ini didukung oleh penelitian Fadrul \& Ridawati (2020); Fauzan \& Sutiono (2017); dan Prihanthini \& Sari (2013) bahwa metode Grover memiliki tingkat akurasi 100\%, dan juga analisi yang tepat untuk memprediksi kebangkrutan.

Penelitian ini menunjukkan bahwa teori sinyal memberikan informasi mengenai prospek perusahaan kedepanya secara transparan pada laporan keuangan. Hal ini terlihat pada metode Grover ialah analisis paling tepat dalam memprediksi kebangkrutan, untuk itu diharap perusahaan mampu mempertahankan dan meningkatkan kinerja untuk kedepanya.

Metode Grover merupakan analisis yang tepat untuk memprediksi kebangkrutan pada perbankan. Selain hasil analisis memberikan tingkat akurasi $100 \%$, yang menyatakan bahwa benar prediksi ini sesuai dengan kenyatan lapangan bahwa perbankan tahun 2015-2019 tidak ada yang mengalami kebangkrutan. Ada yang perlu diperhatikan yaitu beberapa instrumen perhitungan seperti; working capital to total assets (WCTA), dan earning before interest and taxes to total asset (EBITTA). Karena pada uji t parsial kedua variabel tersebut dinilai berpengaruh postif dan signifikan dalam memprediksi kebangkrutan sebuah perbankan.

\section{KESIMPULAN}

Hasil penelitian ini, metode Zmijewski dan Grover terdapat perbedaan analisis prediksi. Hal ini dikarenakan perbedaan instrumen perhitungan. Pada metode Zmijewski memiliki instrumen perhitungan return on asset, debt ratio, dan current ratio. Sedangkan Grover memiliki instrumen perhitungan working capital to total assets, earning before interest and taxes to total asset, dan return on asset. Dengan demikian, diketahui bahwa persamaan jumlah instrumen, dan kesamaan perhitungan rasio ROA tidak akan menghasilkan prediksi kebangkrutan yang sama pula.

Metode Grover merupakan analisi prediksi kebangkrutan yang tepat dalam untuk sektor perbankan. Diketahui Grover menunjukkan rata-rata nilai postif yang artinya tidak ada perbankan yang mengalami kebangkrutan atau dalam kondisi yang sehat. Hal ini sejalan dengan kondisi lapangan yang ada, bahwa tidak adanya sampel perbankan yang mengalami pailit pada tahun 2015-2019. Metode Grover juga memiliki tingkat akurasi yang lebih tinggi daripada metode Zmijewski, yaitu sebesar $100 \%$ dengan tipe error 0\%. Sehingga disimpulkan bahwa Grover merupakan analisis prediksi yang tepat untuk memprediksi kebangkrutan bank konvensional yang terdaftar di Bursa Efek Indonesia tahun 2015-2019. Dengan demikian sektor perbankan harus lebih memperhatikan beberapa rasio keuangan agar terhindar dari kebangkrutan seperti: working capital to total assets, dan earning before interest and taxes to total asset. Karena pada uji t parsial kedua variabel tersebut dinilai berpengaruh postif dan signifikan dalam memprediksi kebangkrutan sebuah perbankan.

Keterbatasan penelitian hanya dilakukan dengan metode Zmijewski dan Grover, dalam kurun waktu lima tahun saja. Untuk itu disarankan bagi peneliti selanjutnya dapat menambah jumlah sampel perusahaan dengan memerpanjang periode penelitian, dan menambahkan beberapa metode-metode prediksi lainnya seperti metode Altman, Ohslon, Springate, Fulmer, dan lain-lain. Sehingga dapat menjawab metode mana yang terbaik dalam memprediksi kebangkrutan sebuah perusahaan.

\section{DAFTAR PUSTAKA}

AlAli, M. S., Alshamali, M. M., AlAwadhi, K. M., \& AlSabah, A. M. (2018). The use of Zmijewski Model in Examining the Financial Soundness of Oil and Gas Companies Listed at Kuwait Stock Exchange. International Journal of Economics, Commerce and Management Research Studies, 1(2), 15-21. www.ijecmrs.com

Aminian, A., Mousazade, H., \& Khoshkho, O. I. (2016). Investigate the Ability of Bankruptcy Prediction Models of Altman and Springate and Zmijewski and Grover in Tehran Stock Exchange. Mediterranean Journal of Social Sciences, 7(4), 208-214. https://doi.org/10.5901/mjss.2016.v7n4s1p208 
Avenhuis, J. O. (2013). Testing the Generalizability of the Bankruptcy Prediction Models of Altman, Ohlson and Zmijewski for Dutch Listed and Large Non-Listed Firms. Journal of Business Administration, Publisher: University of Twente, 38-39.

Baroroh, U. (2012). Analisis Sektor Keuangan terhadap Pertumbuhan Ekonomi Regional di Wilayah Jawa: Pendekatan Model Levine. Jurnal Etikonomi, 11(2), 180-195. https://doi.org/10.15408/etk.v11i2.1892

Dendawijaya, L. (2009). Manajemen Perbankan. Jakarta: Ghalia Indonesia.

Fadrul, \& Ridawati. (2020). Analysis of Method Used to Predict Financial Distress Potential in Pulp and Paper Companies of Indonesia. International Journal of Economics Development Research (IJEDR), 1(1), 57-69. https://doi.org/10.37385/ijedr.v1i1.29

Fauzan, H., \& Sutiono, F. (2017). Perbandingan Model Altman Z- Score , Zmijewski, Springate, dan Grover dalam Memprediksi Kebangkrutan Perusahaan Perbankan. Jurnal Online Insan Akuntan, 2(1), 49-60.

Ghozali, I. (2016). Aplikasi Analisis Multivariate dengan Program SPSS 25. Semarang: Badan Penerbit Universitas Diponegoro.

Gitman, L.J. dan Zutter, C. J. (2011). Principles of Managerial Finance. 13th Edition. Boston: Pearson Education.

Gunawan, B., Pamungkas, R., \& Susilawati, D. (2017). Perbandingan Prediksi Financial Distress Menggunakan Model Altman, Grover dan Zmijewski. Jurnal Akuntansi dan Investasi, 18(1), 119-127. https://doi.org/10.18196/jai.18164

Habriyanto. (2011). Intermediasi Perbankan Syariah pada Bank Syariah Mandiri Cabang Jambi. Jurnal Kajian Ekonomi Islam dan Kemasyarakatan, 3, 57-74. https://media.neliti.com/media/publications/220431-none.pdf

Halimatusyakdiah, Kosim, A., \& Meirawati, E. (2015). Analisis Financial Distress pada Industri Kosmetik yang Terdaftar di Bursa Efek Indonesia (BEI) untuk Memprediksi Potensi Kebangkrutan Perusahaan. Akuntabilitas: Jurnal Penelitian Dan Pengembangan Akuntansi, Vol $9(2)(2), 125-140$.

Husein, M. F., \& Pambekti, G. T. (2015). Precision of the Models of Altman, Springate, Zmijewski, and Grover for Predicting the Financial Distress. Journal of Economics, Business \& Accountancy Ventura, 17(3), 405. https://doi.org/10.14414/jebav.v17i3.362

Kasmad. (2018). Perubahan Return On Asset (ROA) Yang Diakibatkan Adanya Perubahan Pada Non Performing Loan (NPL) Dan Loan To Deposit Ratio (LDR) Pada PT. Bank Negara Indonesia Persero, Tbk. Jurnal Kreatif: Pemasaran, Sumberdaya Manusia, Dan Keuangan, 6(1), 59-72.

Kurniawati, L., \& Kholis, N. (2016). Analisis Model Predeksi Financial Distress pada Perusahaan Perbankan Syariah di Indonesia. Syariah Paper Accounting FEB UMS. http://hdl.handle.net/11617/7341

Mulyati, S., \& Ilyasa, S. (2020). The Comparative Analysis of Altman Z-Score , Springate , Zmijewski , and Internal Growth Rate Model in Predicting the Financial Distress ( Empirical Study on Mining Companies Listed on Indonesia Stock Exchange 2014-2017). Kinerja, 24(1), $82-95$.

Munawarah, M., \& Hayati, K. (2019). Accuracy of Springate, Zmijewsky and Grover As Logistic 
Amel Dewi Utari. Analisis Perbandingan Metode Zmijewski dan Metode Grover dalam Memprediksi Kebangkrutan Bank yang Terdaftar pada BEI 2015-2019.

Models in Finding Financial Difficulty of Financing Companies. Accruals, 3(1), 1-12. https://doi.org/10.35310/accruals.v3i1.36

Pakdaman, H. (2018). Investigating the ability of Altman and Springate and Zmijewski and grover bankruptcy prediction models in Tehran Stock Exchange. Espacios, 39(14).

Pangkey, P. C., Saerang, I. S., Maramis, J. B., Ekonomi, F., Bisnis, D., Manajemen, J., Sam, U., \& Manado, R. (2018). Analisis Prediksi Kebangkrutan dengan Menggunakan Metode Altman dan Metode Zmijewski pada Perusahaan Bangkrut yang Pernah Go Public di Bursa Efek Indonesia. Jurnal EMBA: Jurnal Riset Ekonomi, Manajemen, Bisnis dan Akuntansi, 6(4), 3178-3187. https://doi.org/10.35794/emba.v6i4.21292

Prihanthini, N. M. E., \& Sari, M. M. R. (2013). Analisis Prediksi Kebangkrutan dengan Model Grover, Altman Z-Score, Springate dan Zmijewski Pada Perusahaan Food and Beverage Di BEI. E-Jurnal Akuntansi, 5(2), 417-435.

Pustylnick, I. (2012). Restructuring the Financial Characteristics of Projects in Financial Distress. Global Journal of Business Research, 6(2), 125-135.

Putra, I. G. S., \& Septiani, R. (2017). Analisis Perbandingan Model Zmijewski dan Grover Pada Perusahaan Semen di BEI 2008-2014. Jurnal Riset Akuntansi dan Keuangan, 4(3), 1143-1154. https://doi.org/10.17509/jrak.v4i3.4667

Putri, A. I. (2019). Analisis Perbandingan Model Zmijewski dan Model Grover Dalam Memprediksi Financial Distress Pada Sub Sektor Metal And Allied Products di BEI. Skripsi Fakultas Ekonomi - Universitas Islam Riau.

Qamruzzaman, M., \& Jianguo, W. (2016). Analysis of Financial Distress on Micro Finance Institutions (Mfis) in Bangladesh: a Case Study of Grameen Bank. Commonwealth Journal of Commerce \& Management Research, 3(12), 1-15.

Syamni, G., Majid, M. S. A., \& Siregar, W. V. (2018). Bankruptcy Prediction Models and Stock Prices of the Coal Mining Industry in Indonesia. Etikonomi, 17(1), 57-68. https://doi.org/10.15408/etk.v17i1.6559

Tuvadaratragool, S. (2013). The Role of Financial Ratios in Signalling Financial Distress : Evidence from Thai Listed Companies. Tesis. Southern Cross University., 216. 